\title{
Tea garden landscape ecological planning take yellow tea garden of Guangzhou Conghua as an example
}

\author{
Yue Zhong, China \\ Email:178657692@qq.com
}

Keywords: Tea; landscape design; ecological tea garden

Abstract. The ecological tea garden landscape design has not formed a relatively integrated theoretical system, our common form of tea garden is tea-picking garden, science and technology demonstration tea garden and multiple integrated tea garden. Taking Conghua district landscape yellow tea garden for example, set out to ecological tea garden landscape design, respectively, terrain, water, architectural sketches, plants and other elements of landscape to design and summarize tea garden landscape ecological planning, aimed to provide feasible basis of yellow tea garden and future ecological tea garden tea garden, giving services to local sightseeing tour.

\section{Overview}

Conghua district located in central of Guangdong Province, northeast of Guangzhou city, which is the Pearl River Delta to northern Guangdong transition zone, in the east conghua district is border on Zengcheng and Longmen County, its south is suburb of Guangzhou, its west boundary Qingyuan City, north connected Buddha Kong and Xinfeng County, mostly is hilly lowlands. Liang Town is located in the northern part of Conghua district, 25km from Conghua district. Yellow tea garden is 1135 meters above sea level, which locates in the the middle of Lianxi Village, through a small playground road of the village can reach the top, which is the second highest mountain in Conghua, along the road is charming rurality, flowers, water coward. Yellow tea Conghua stream River is the main source, located in the mountain village "Tou Village," hence the name. mountaintop is about 1000 meters from Tou village, substantially no step to reach. [1] Tea plant in the long process of evolution, gradually formed a hi wet fear of floods, thermophilic afraid of cold, afraid of the sun light, hi acid afraid alkali growth characteristics. It is suitable growth in high mountains, dense forests, full diffused light, fertile soil, and acidic environment.

Neighboring Mipu village of Liangkou town Conghua district is 800 acres of woodland, which has been started into the proposed plan "tea floral scene" modern agricultural eco-tourism park. Yellow tea garden if planning to ecological tea garden, which will be able to enhance the environment and landscape effects. Many varieties of tea plants in this district, there is Camellia semiserrata Chi, oil-tea camellia, Safflower oil and white tea, etc., the main road along the edge of the main breeding camellia flower, red and white flowers and green leaves set off against each other in flowering time, attractive harvest fruits as blossoms fade, which is loved by the people. ${ }^{[2]}$

Terrain, altitude and temperature of Yellow tea garden is similar to Mipu village, and very suitable for tea cultivation. The design aims to create a green modern ecological tea landscape, which has aesthetic and economic connotation landscape, eventually to construct a set of landscape, tourism, recreation, economic production as one of the diversity of landscape ecological park, to provide an innovative, practical and functional ecological garden construction mold, also ideal place of Return to Nature, self-cultivation, edify sentiment provide for people. 


\section{The purpose and significance of ecological tea garden planning and design}

Tea has a strong social function, induction of 21 of its most important aspects, such as the Friends of tea, tea instead of wine, tea promote integrity, tea painting, tea performance, tea tourism, tea banquet, tea and fitness. ${ }^{[3]}$ Construction of ecological tea not only promote rural modernization construction and ecological civilization construction, but also providing a versatile recreation park for people to relax.

Conghua people love tea, tea quality is closely related to environmental conditions. Tea plant is not just an economic plant but an ornamental plant, yellow tea garden mountainous' location, creating a unique tea culture and cultural landscape, first brought an significant agricultural economic benefits, but more importantly is landscape ecological benefits. Ecological Tea Garden can enjoy the experience the beauty and its culture of the tea garden. Tea production combine leisure and tourism in future, which can get good results in ecological, economic, social benefit. Eco-tourism tea garden can promote local economic sources also resolve the majority of farmers; broaden employment channels for farmers and improve the overall quality of workers; Eco-tourism tea garden can attract people to go to rural tourism, with the majority of farmers live together, talk to each other, exchange ideas, transmit new ideas; enable local farmers to pay more attention to the local culture of mining and protection to thousands of years of rural preservation of ancient culture and folk customs; but also to protect the ecological environment, which leading people to create a more more complex natural landscape respect the environment. ${ }^{[4]}$ Achieve a win-win ecological benefits, economic benefits, social benefits and cultural benefits.

\section{Huang tea garden landscape design principles}

\section{Principles of local conditions}

Characteristics of full understanding of the local environment, constructing along mountain, local architectural style with traditional architectural style uniform, perform good rustic style is the throughout landscape planning.

\section{ecological principles}

Make full use of the local ecological environment resources, and actively create a multi-level landscape; ecological tea tourist activity behavior within certain rules let tourism activities and environmental protection to maintain relative dynamic balance, so the impact on the environment and to reduce the damage in a minimum, simultaneously to promote natural resources and ecosystems balanced development.

\section{integrity and the principle of unity}

Throughout the landscape planning and design to fully consider the local overall layout, ensure unity and concord avoid much difference, each partition different but linked.

\section{principles of combining natural and cultural landscapes}

Making landscape planning and design, analyzing the local cultural landscape or natural landscape which is dominated, and finding the main elements and characteristics as the core of the whole performance, but also consider other factors, such as, native vegetation, poultry farm animals, cultural history, folk customs, etc. to show the unique geographical features, to achieve the perfect combination of natural landscape and cultural landscape.

\section{combining Functional and ornamental principle}

Integrating a sightseeing, experience picking, amenity forest when plant Landscape Planning and Design, Landscape architecture articles based on its function, with good ornamental, combining 
functional and esthetics to services landscape, and the landscape features are showing in the performance.

\section{Huang tea garden Ecological Landscape Planning Idea}

Huang tea garden locates in Liangkou town, tea garden area are full of mountains, valleys connected minor grade hills, high forest coverage, layer upon layer, a beautiful ecological environment, rich landscape elements with local specialties, good visual effect, so it has great tourism development value. Thus making ecological tea garden landscape design should consider a combination of organic architectural design, landscape design and other resources, promote the combination of ecological and tea culture, creating a set of tea cultivation, production, culture, tourism as an integrated ecological tea garden, so that let visitors have a fully local cultural experience in the view of tea and enjoy tea.

\section{Road, terrain, water body design}

Striving to natural flow, twists and turns in order to have different scenes in steps when road design, combination of roads, bridges, stone steps, in various forms so it can avoid monotony; In topographical design, full the use of undulating terrain, constituting natural topography to form the skeleton of the park; or in perfectly combination the stairs, plants, architectural sketches, dividing into several different garden space of park, creating a beautiful quiet relaxing environment. Yellow tea garden has a natural advantage of vitality water, one stream river water can be introduced from Xitou village, water with topography, can enrich the landscape, combining static and dynamic in natural changes makes landscape more active.

\section{Atmosphere Tea Culture}

With the vigorous development of tourism in recent years, with a specific geographical and cultural landscape as the basis of the tourist area is very important. Cultural landscape is the human in order to meet some practical needs, using materials provided by nature, and by superimposing the result of human activity on the natural landscape formed. In order to create an atmosphere, it needs a strong historical and cultural landscape and natural tea-based, and the history of tea culture, tea folk cleverly integrated into the design, further enrich the connotation of tea culture theme landscape. ${ }^{[5]}$

\section{Design landscape architecture articles}

Seek the landscape architecture articles and landscape sketch with surrounding environment unity. When designing landscape architecture articles, reflecting the characteristics of yellow tea, vernacular architecture and rich flavor of tea culture on its shape, color and other aspects, at the same time, give full consideration to the characteristics of human behavior at the park activity and resting. Showing the beautiful countryside, ecological tea culture should as a guide, with the material, color, image to demonstrate its uniqueness, so as to achieve harmony with the surrounding landscape and ultimately to better express a different landscape. Make some pick tea, make tea, sell tea, drink tea and tea collection sculptures, and the material chosen to local bamboo, wood, stone based. ${ }^{[6]}$ Combination of rural culture and rural features and characteristics, and design agricultural tools in architecture articles, so that both show a local farm characteristics, but also with ecotourism effect.

\section{Design of plant cultivation}

Ecological tea is a simulate tea natural ecological communities and set up multi-species, multi-level artificial ecosystem composition, which uses highly intensive management of multispecies to tea-based, configuration of other crops to local conditions, the formation of a multi-level complex three-dimensional cultivation give full play to the complementary nature of various plants, efficient use 
of all available natural resources, so that all crops can be mutually beneficial symbiosis, constitutes a reasonable ecosystem, to achieve maximum efficiency in a limited space and the shortest time. ${ }^{[5]}$

Create ecological tea garden landscape, not only to plan the cultivation of tea, but also handle the planning area and the surrounding flora and fauna of the relationship, to form a complete landscape. Landscape shape should in conjunction with a variety of local cultural characteristics, a distinctive tea culture as main body, add the local endemic species and native species of tea to create best landscape mode. ${ }^{[7]}$

Yellow tea garden area has a rich plant resources, the appropriate choice of native plants is feasible program of ecological tea garden. During ecological tea plant configuration, combining trees, shrubs, rattan wood, herbal plants to grasp colors at all seasons; for color formulation blended in with the plant diversity. Upper Landscape, banyan trees can be used, Ficus microcarpa、Ficus altissima、Ficus altissima 、Delonix regia 、Jacaranda mimosifolia D. Don、Erythrina crista-galli Linn. 、Michelia alba DC. 、Sterculia lanceolata Cav. 、Senna surattensis (Burm. f.) H. S. Irwin et Barneby、 Magnolia liliflora Desr etc., cause the highest concentration of large shade, water conservation excellent ornamental tree the lower selection Bougainvillea, Bougainvillea spectabilis Willd. 、 Bambusa multiplex 'Fernleaf' 、 Allemanda neriifolia Hook. 、Osmanthus fragrans (Thunb.) Lour. 、Duranta repens L. 、Fagraea ceilanica Thunb. 、Loropetalum chinense var.rubrum 、 Calliandra haematocephala Hassk. Hibiscus rosa-sinensis Linn. and other shrubs and can adapt to the local environment, natural style of native plants to highlight fun. Combining these plants with a certain artistic techniques, give full play to its shape, line, color and other natural beauty creation, formed plants and natural landscape, plants and buildings, plant and other roads with a combination of landscape, giving people association, developing the spirit of the tea ceremony plant interpenetration, showing truly natural and ecological beauty.

\section{Conclusion}

Tea garden landscape ecological planning is the inevitable result of modern society, leisure tourism mountain landscape planning is a new type of landscape, with obvious regional characteristics and selectivity restrictive conditions, during the planning and design, whether in use functional or aesthetic features of landscape, think of different projects and regional environmental conditions, due to show its unique style, but the overall plan should be follow ecological, recreational, sustainable development of this principle. Reasonable layout, planning, park setting matched landscape, attention and reconstruction of ecological tea garden construction, aim to express create a objective ecological tea landscape, for yellow tea garden and even for other similar regional scenic spot to achieve sustainable development has a great significance.

\section{References}

[1] http://baike.sogou.com/v59718433.htm

[2] Chundi Yang, Guangdong Conghua. Tea fragrance scene_study of ecological agriculture sightseeing planning, Journal of tropical forest.3.2014.

[3] Fei Wu, The research of Ecological tea garden landscape design, Master degree theses of master of Hunan agricultural university.11.2013

[4] Li Chen, The development of tea culture landscape present situation and problems existed, Modern Gardening.7.2014 
[5] Analys of tea culture's expression and construction in the ecological tea garden landscape, Yunnan Agriculture University. 2.2015

[6] Huaji Sun, The research of landscape planning in Midi tea village, Mojiang County in yunnan province, The Chinese local-style dwelling houses. 8.2004

[7] Chen Li, Discussions and Suggestions of tea culture landscape design , Modern Gardening. 5, 2014 